\title{
Antiangiogenic effect of crocin on breast cancer cell MDA-MB-231
}

\author{
Shuang-Shuang Chen ${ }^{1,2 \#}$, Yuan Gu ${ }^{3 \#}$, Fang Lu ${ }^{4 \#}$, Dan-Ping Qian ${ }^{5}$, Ting-Ting Dong ${ }^{5}$, Zhong-Hai Ding ${ }^{1}$, \\ Shuang Zhao ${ }^{1}$, Zheng-Hong Yu ${ }^{1}$ \\ ${ }^{1}$ Department of Medical Oncology, Jinling Hospital, Medical School of Nanjing University, Nanjing 210002, China; ${ }^{2}$ Department of Medical \\ Oncology, Huai'an Cancer Hospital, Huai'an 223200, China; ${ }^{3}$ Shanghai Medical School of Fudan University, Shanghai 200433, China; ${ }^{4}$ Usc School \\ of Engineering, University Park, Los Angeles, CA, USA; ${ }^{5}$ Nanjing University of Chinese Medicine, Nanjing 210023, China \\ Contributions: (I) Conception and design: SS Chen, Y Gu, F Lu, ZH Yu; (II) Administrative support: ZH Yu; (III) Provision of study materials \\ or patients: DP Qian, TT Dong, ZH Ding, ZH Yu; (IV) Collection and assembly of data: SS Chen, Y Gu, Y Gu, S Zhao; (V) Data analysis and \\ interpretation: SS Chen, Y Gu, S Zhao; (VI) Manuscript writing: All authors; (VII) Final approval of manuscript: All authors. \\ \#These authors contributed equally to this work. \\ Correspondence to: Zheng-Hong Yu, MD. Department of Medical Oncology, Jinling Hospital, Medical School of Nanjing University, No. 305, \\ Zhongshan East Road, Xuanwu District, Nanjing 210002, China. Email: yuzhenghong1999@163.com.
}

\begin{abstract}
Background: Crocin is the major chemical constituent of the Chinese herb saffron. A number of studies have indicated that crocin induces an antitumor effect by inhibiting proliferation and inducing the apoptosis of tumor cells. However, the effect of crocin on tumor angiogenesis remains unknown.

Methods: The effects of prolonged crocin exposure on breast cancer cell MDA-MB-231, human umbilical vein endothelial cells (HUVECs) and mice were examined.

Results: Crocin had a profound effect on the morphology and proliferation rate of MDA-MB-231 and HUVECs. Furthermore, crocin induced apoptosis and cell cycle arrest at the G2/M phase in MDAMB-231 cells in a dose-dependent manner. This confirms that crocin induces the inhibition of HUVECs. Furthermore, the expression of CD34 in tumor tissues decreased after crocin treatment.

Conclusions: Crocin has an anti-angiogenesis effect that may be correlated to the decreased expression of CD34. Crocin is likely to be involved in the regulation of molecules in the angiogenesis pathway.
\end{abstract}

Keywords: Breast cancer cell MDA-MB-231; crocin; human umbilical vein endothelial cell (HUVEC); angiogenesis; CD34; anti-angiogenesis; proliferation

Submitted Jul 19, 2019. Accepted for publication Oct 08, 2019.

doi: $10.21037 /$ jtd.2019.11.18

View this article at: http://dx.doi.org/10.21037/jtd.2019.11.18

\section{Introduction}

Breast cancer is one of the three most common cancers worldwide (1). Compared to lung cancer, which is the leading cause of cancer death among females in more developed countries, breast cancer remains the leading cause of cancer death among females in less developed countries (2). According to the expression level of estrogen receptor (ER), progesterone receptor (PR) and human epidermal growth factor 2 (Her-2), breast cancer can be divided into four types: Luminal A, Luminal B, Her-2, and triple negative breast cancer (TNBC). Early breast cancer can be removed by primary conventional surgery. However, this is not optimal for all patients. Depending on the clinical tumor subtype, additional therapeutic backbones include endocrine therapy, targeting anti-HER2 therapy, radiotherapy, chemotherapy and immunotherapy (1). Neoadjuvant therapy has also been commonly used for some patients. Although the treatment of breast cancer has been improved, the adverse reactions of radiotherapy, chemotherapy and drug resistance always follows. Consequently, many patients suffer from recurrence and metastasis after treatment. Hence, novel therapeutics to treat breast cancer is thereby highly needed.

In recent years, work in the field of anti-tumor has been sparked by the increased interest in traditional Chinese 
medicine (TCM). TCM can ameliorate the toxicity of chemotherapy, regulate immune function, inhibit tumor growth and prevent recurrence. It not only improves the quality of life of patients, but also enables patients to achieve long-term survival. Crocin is a diester formed from the disaccharide gentiobiose and the dicarboxylic acid crocetin. Crocin is a water-soluble carotenoid (polyene dicarboxylic acid monosaccharide ester). This compound is the major constituent and the main dark red pigment of saffron. Saffron is a rare and valuable Chinese herbal medicine, which is a product naturally derived from the dried stigma of the Crocus sativus flower. In TCM, saffron can be used for multiple purposes, including sweating, digestion assistance, sedative, expectorant, impotence, abortion, and treatments for vomiting, cardiovascular disease and cancer (3). Previously, it has been reported that saffron has effects in preventing multiple diseases, such as atherosclerosis, tumor, arrhythmia and osteoporosis (4). In light of this, the anti-tumor effect of crocin has also been confirmed by a number of studies in recent years. Furthermore, crocin can inhibit the proliferation and induce the apoptosis of various tumor cells, such as lung cancer (5), liver cancer (6), gastric adenocarcinoma (7), bladder cancer (8), and leukemia $(9,10)$. In addition, it has been shown that paclitaxel or radiotherapy combined with crocin has a synergistic effect in inducing the apoptosis of human MCF7 breast cancer cells, which results in cell cycle arrest by lowering cyclicD1 $(11,12)$.

The present study explored the effects of crocin on the proliferation and apoptosis of TNBC cells, such as the MDA-MB-231 cell line. In addition, the effects of crocin on the proliferation, migration ability and tubule formation ability of human umbilical vein endothelial cells (HUVECs) were explored.

\section{Methods}

\section{Cell culture and reagents}

Human breast cancer cell MDA-MB-231 and HUVECs (American Type Culture Collection, Manassas, VA, USA) were cultured in RPMI 1640 and DMEM (Hyclone, Cramlington, UK), supplemented with $10 \%$ bovine calf serum, $100 \mu \mathrm{g} / \mathrm{mL}$ of penicillin and $100 \mu \mathrm{g} / \mathrm{mL}$ of streptomycin (Gibco, Carlsbad, CA, USA), in an incubator with $5 \% \mathrm{CO}_{2}$ at $37{ }^{\circ} \mathrm{C}$. Crocin was purchased from SigmaAldrich (St. Louis, MO, USA) and stored at $4{ }^{\circ} \mathrm{C}$ at a stock concentration of $50 \mathrm{mM}$ in phosphate buffered saline (PBS) with $0.125 \mathrm{mg} / \mathrm{mL}$ ethylenediaminetetraacetic acid. The apoptosis and cell cycle analysis kits were purchased from Nanjing KeyGen Biotech (Nanjing, China). The transwell chamber was purchased from Corning Costar (USA). The anti-rabbit/mouse universal immunohistochemistry kit G1003-2 was purchased from Dako (Denmark). The rabbit IHC secondary antibody kit was purchased from Maixin Biotechnology Development Co., Ltd. (Fuzhou, China). Both were stored at $4{ }^{\circ} \mathrm{C}$. Clean BALB/C female nude mice ( $\mathrm{n}=10,4-6$ weeks old, approximately $20 \mathrm{~g}$ ) were purchased from Nanjing Military Region Nanjing General Hospital Comparative Medicine Department, Production license number: SCXK (Army) 2012-0014, Use license number: SYXK (Army) 2012-0047.

\section{MTT assay}

MDA-MB-231 cells and HUVECs were seeded in 96 -well plates at a density of $4 \times 10^{4}$ cells $/ \mathrm{mL}$ and $2.5 \times 10^{4}$ cells $/ \mathrm{mL}$ in $200 \mu \mathrm{L}$ of medium. After 24 hours, these cells were synchronized by starvation in serum-free medium before being replaced by fresh medium with different concentrations of crocin $(0,1,2,4,8$ and $16 \mathrm{mg} / \mathrm{mL})$. Each concentration of crocin was added into three wells. Then, $20 \mu \mathrm{L}$ of MTT $(5 \mathrm{mg} / \mathrm{mL})$ was added into each well after 24, 48 and 72 hours of treatment. After four hours, $150 \mu \mathrm{L}$ of crystalline in dimethyl sulfoxide was added to each well. Absorbance (optical density, OD) at $570 \mathrm{~nm}$ was measured using a microplate reader. Cell proliferation inhibitory rate $(\%)=(1-$ OD value in the treated group/ OD value in the control group) $\times 100 \%$. The $50 \%$ inhibitory concentration (IC50) after 48 hours of crocin treatment, which was selected for subsequent experiments, was calculated based on the MTT assay. Each experiment was performed in triplicate.

\section{Apoptosis and cell cycle by flow cytometry}

MDA-MB-231 cells were seeded in 6-well plates at a density of $1.5 \times 10^{5}$ cells $/ \mathrm{mL}$ for 24 hours. Then, the medium with crocin was added to the wells that contained these cells for 48 hours. For the detection of apoptosis, cells were collected by trypsinization, washed twice with PBS, suspended in $500 \mu \mathrm{L}$ of binding buffer, and consecutively added with $5 \mu \mathrm{L}$ of Annexin V-FITC and $5 \mu \mathrm{L}$ of propidium iodide. Following incubation for 10 minutes in the dark at room temperature, cells were subjected to flow cytometry analysis. For the cell cycle analysis, cells were washed with 
PBS and fixed in cold $70 \%$ ethanol. After washing with PBS, $100 \mu \mathrm{L}$ of ribonuclease A was added to the wells that contained these cells, incubated at $37^{\circ} \mathrm{C}$ for 30 minutes, and subjected to flow cytometry analysis after the addition of $400 \mu \mathrm{L}$ of $1 \times$ Annexin $\mathrm{V}$ Binding Buffer. The red fluorescence was recorded at an excitation wavelength of $488 \mathrm{~nm}$. Each experiment was performed in triplicate.

\section{Detection of migration ability of HUVECs by Transwell assay}

Next, $2 \times 10^{4}$ HUVECs were seeded in the above Transwell chamber with $200 \mu \mathrm{L}$ of medium and different concentrations of crocin $(0,1,2$ and $4 \mathrm{mg} / \mathrm{mL})$, and plated in the bottom chamber of the Transwell with $600 \mu \mathrm{L}$ of fresh medium containing $10 \%$ bovine calf serum. Each concentration of crocin was added into three wells. Then, these cells were cultured at $37{ }^{\circ} \mathrm{C}$ with $5 \%$ $\mathrm{CO}_{2}$ for 24 hours. Cells under the membrane were fixed in $4 \%$ paraformaldehyde and stained with crystal violet after removing cells above the membrane. Each filter was randomly selected for three fields of view, and the number of cells that passed through the membrane were counted and photographed under a microscope. Migration rate $(\%)=$ (the number of migrated cells in the treated group/the number of migrated cells in the control group) $\times 100 \%$. Each experiment was performed in triplicate.

\section{Endotbelial cell tubule formation assay}

Fifty $\mu \mathrm{L}$ of Matrigel (BD Biosciences) per well of the 96well plate was allowed to solidify for 30 minutes at $37{ }^{\circ} \mathrm{C}$. Then, $2 \times 10^{4}$ of HUVECs were added to the medium in each well with different concentrations of crocin $(0,2,4$ and $6 \mathrm{mg} / \mathrm{mL}$ ), followed by incubation at $37^{\circ} \mathrm{C}$ for four hours. Each concentration of crocin was added into three wells. Each well was randomly selected for three fields of view, and the number of tube formation was observed using a microscope $(\times 20)$. Each experiment was performed in duplicate.

\section{Establishment of the subcutaneous tumor model}

A total of $10^{7}$ MDA-MB-231 cells per mouse were subcutaneously inoculated in the right thigh of 10 4-weekold female mice. These mice were randomly divided into two groups when all mice tumor volumes reached $300 \mathrm{~mm}^{3}$ after 15 days. Then, $5 \mathrm{mg} / \mathrm{mL}$ of crocin and an equivalent volume of normal saline were injected into the treatment and control group by intraperitoneal injection every two days, for a total of seven doses, respectively. The mass of the long diameter and short diameter was measured using a Vernier caliper before each administration. The primary subcutaneous tumors were harvested and processed to tumor sections for immunohistochemical (IHC) staining, in order to detect the expression of Ki-67 and CD34. Tumor volume $\left(\mathrm{mm}^{3}\right)=$ long diameter $(\mathrm{mm}) \times$ short diameter $(\mathrm{mm})$ $\times$ short diameter $(\mathrm{mm}) / 2$.

\section{Immunohistochemical analysis}

EnVision ${ }^{\mathrm{TM}}$ immunohistochemical staining was used. Then, mice were sacrificed, and the subcutaneously transplanted tumor was embedded in paraffin. Afterwards, the paraffin sections were sliced at $65^{\circ} \mathrm{C}$ for one hour, and dewaxed and hydrated according to the conventional method. Then, these were repaired with citrate antigen, soaked in hydrogen peroxide at room temperature for 30 minutes, and added with fetal bovine serum for blocking at $37^{\circ} \mathrm{C}$ for 30 minutes. Afterwards, these were rinsed with PBS, and added with the anti-rabbit anti-human CD34 antibody and rabbit anti-human Ki-67 antibody overnight at $4{ }^{\circ} \mathrm{C}$. Subsequently, these were rinsed again with PBS, incubated with rabbit universal secondary antibody, and incubated at $37^{\circ} \mathrm{C}$ for 30 minutes. Then, these were added with diaminobenzidine $(\mathrm{DAB})$, washed, and underwent hematoxylin counterstaining, gradient alcohol dehydration, and neutral gum seal. The results were judged, as follows: brownish yellow was positive in the cytoplasm or nucleus, and each brown-yellow signal could be used as a single, countable positive expression. The three most densely stained areas were determined prior to low magnification (100 times). Then, the number of positive expression signals were counted in the high-power field (200 times), taking the mean of the three fields.

The final result of the sample expression are as follows. The indistinguishable or unclear stained brown-yellow particles were not counted. In the double-blind method, each slice was counted by two pathologists. Recounting was performed when the count results differed by more than $10 \%$.

The quantitation of the CD34 staining was presented in MVD, which was measured using a previously described method $(13,14)$. Individual microvessels were counted at high power $(\times 200$ field $)$ in an adequate area. CD34 positively stained endothelial cells or clusters that separated 

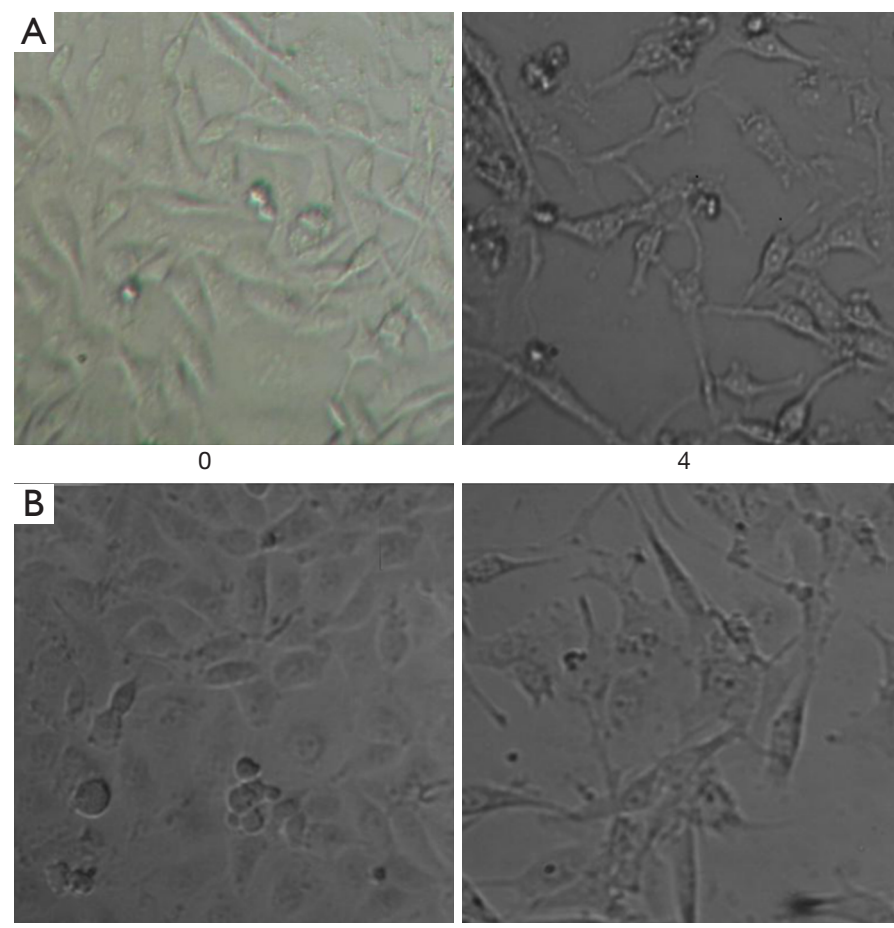

0

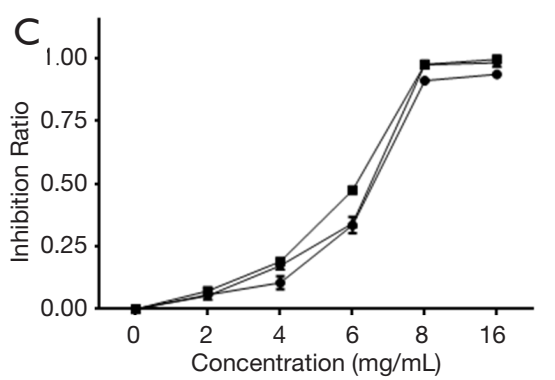

4

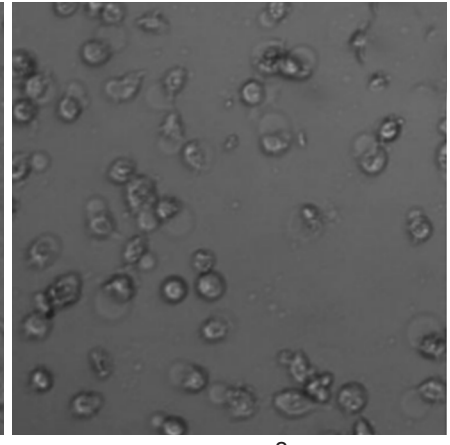

8

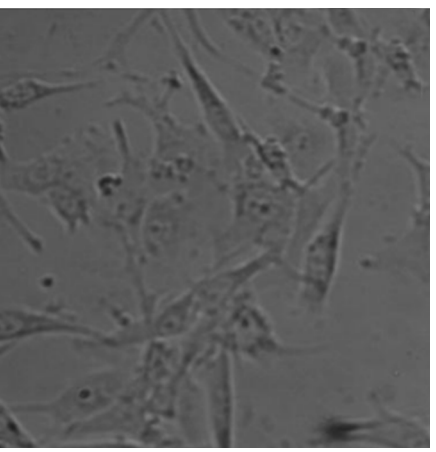

4

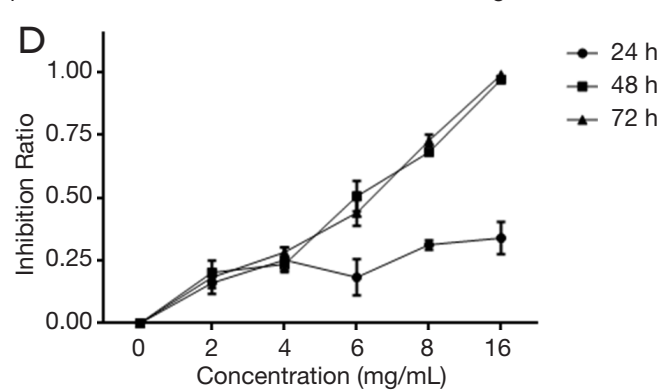

Figure 1 Effect of crocin on the morphology and proliferation of cultured MDA-MB-231 and HUVECs. The morphology of MDAMB-231 (A) and HUVECs (B) significantly changed as the concentration increased. Crocin inhibited the proliferation of MDA-MB-231 (C) and HUVECs (D) in a dose-dependent manner. HUVECs, human umbilical vein endothelial cells.

from adjacent vessels were counted as a single microvessel, even in the absence of the vessel lumen. Five randomly selected "hot spot" fields were counted from each tumor (at least three tumors per mouse group). Data were presented as mean \pm standard deviation (SD) in the figure.

\section{Statistical analysis}

Data were analyzed using the SPSS v20.0 software package (SPSS Inc., Chicago, IL, USA) and expressed as mean \pm SD. Single-factor analysis of variance was performed and the multiple comparisons were analyzed using the LDS method. A P value of $<0.05$ was considered statistically significant.

\section{Results}

\section{Crocin inbibits the proliferation of MDA-MB-231 cells and HUVECs}

The present results revealed that crocin not only changed the morphology, but also decreased the cell number of both MDA-MB-231 cells and HUVECs. In order to further confirm these observations, the cell proliferation was determined by MTT assay. Crocin significantly inhibited the proliferation of MDA-MB-231 cells and HUVECs in a dose-dependent manner (Figure $1 A, B$ ). When the concentration reached $16 \mathrm{mg} / \mathrm{mL}$, almost all cells died. The inhibitory effect of crocin at 48 hours was much stronger 
Table 1 Effect of crocin on proliferation of MDA-MB-231 cells

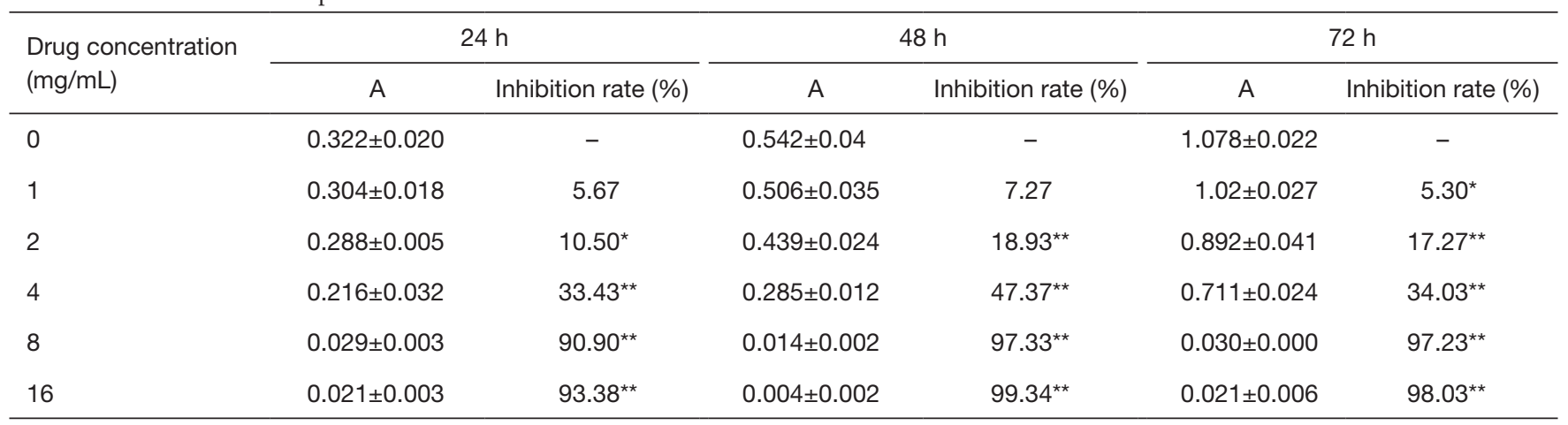

Compared with the control group, ${ }^{\star} \mathrm{P}<0.05,{ }^{\star \star} \mathrm{P}<0.01$.

Table 2 Effect of crocin on proliferation of HUVEC cells (48 h)

\begin{tabular}{lcc}
\hline Groups $(\mathrm{mg} / \mathrm{mL})$ & $\mathrm{A}_{570}$ & Inhibition rate $(\%)$ \\
\hline Control group & & - \\
0 & $0.821 \pm 0.089$ & \\
Crocin group & & 15.0 \\
1.0 & $0.698 \pm 0.011$ & 18.0 \\
2.0 & $0.673 \pm 0.005^{\star *}$ & 38.6 \\
4.0 & $0.504 \pm 0.042^{\star \star}$ & 66.1 \\
8.0 & $0.278 \pm 0.015^{\star \star}$ & 95.4 \\
16.0 & $0.038 \pm 0.008^{\star *}$ & \\
\hline
\end{tabular}

Compared with the control group, ${ }^{\star \star} \mathrm{P}<0.01$.

than that at 24 and 72 hours, and the IC50 value at 48 hours was approximately $5 \mathrm{mg} / \mathrm{mL}$ (Table 1, Figure 1C). Similar inhibitory effects of crocin were also observed in HUVEC cells at 48 and 72 hours, but not at 24 hours. The IC50 value at 48 hours was approximately $5.97 \mathrm{mg} / \mathrm{mL}$ (Table 2, Figure 1D). The drug concentration of the subsequent experiment was according to the IC50 value.

\section{Crocin induces apoptosis and cell cycle arrest at the $G_{2} / M$} phase in MDA-MB-231 cells

In order to determine whether crocin reduced cell viability via the increase in apoptosis, the cell apoptosis in MDA-MB-231 cells treated with crocin were determined using Annexin V-FITC staining, followed by flow cytometry analysis (Figure 2). Interestingly, crocin significantly induced the apoptosis in MDA-MB-231 cells in a dose-dependent manner (Figure $2 \mathrm{~A}$, Table 3). In addition, the treatment of MDA-MB-231 cells with crocin also resulted in cell cycle arrest at the $G_{2} / M$ phase in a dose-dependent manner (Figure 2B, Table 3). These results show that one of the mechanisms by which crocin inhibits MDA-MB-231 breast cancer cell proliferation is via the induction of cell apoptosis and cycle arrest.

\section{Crocin decreases the migration ability of HUVECs}

Through the Transwell assay, it was found that crocin could decrease the migration ability of human UVECs. The number of migrating cells gradually decreased as the crocin concentration increased. Furthermore, the number of migrating cells was significantly lower, when compared to the control group, and the difference was statistically significant $(\mathrm{P}<0.05$; Figure $3 A$, Table 4$)$.

\section{Crocin inbibits endothelial cell tubule formation}

The present study revealed that crocin reduced the tubule formation ability of human UVECs. In order to further confirm these observations, tubule formation assay was performed. Lumen formation was quantified by counting the number of complete lumen formations of vascular endothelial cells. When the concentration of crocin was 2.0, 4.0 and $6.0 \mathrm{mg} / \mathrm{mL}$, lumen formation was inhibited by $14.7 \%, 77.4 \%$ and $87.3 \%$, respectively, and the difference was statistically significant. This result revealed that crocin can inhibit the tubule formation of HUVECs in a dose dependent manner (Table 5, Figure 3B).

\section{Crocin inbibits the proliferation of $M D A-M B-231$ cell transplanted tumors in mice}

In order to determine whether crocin can inhibit the 

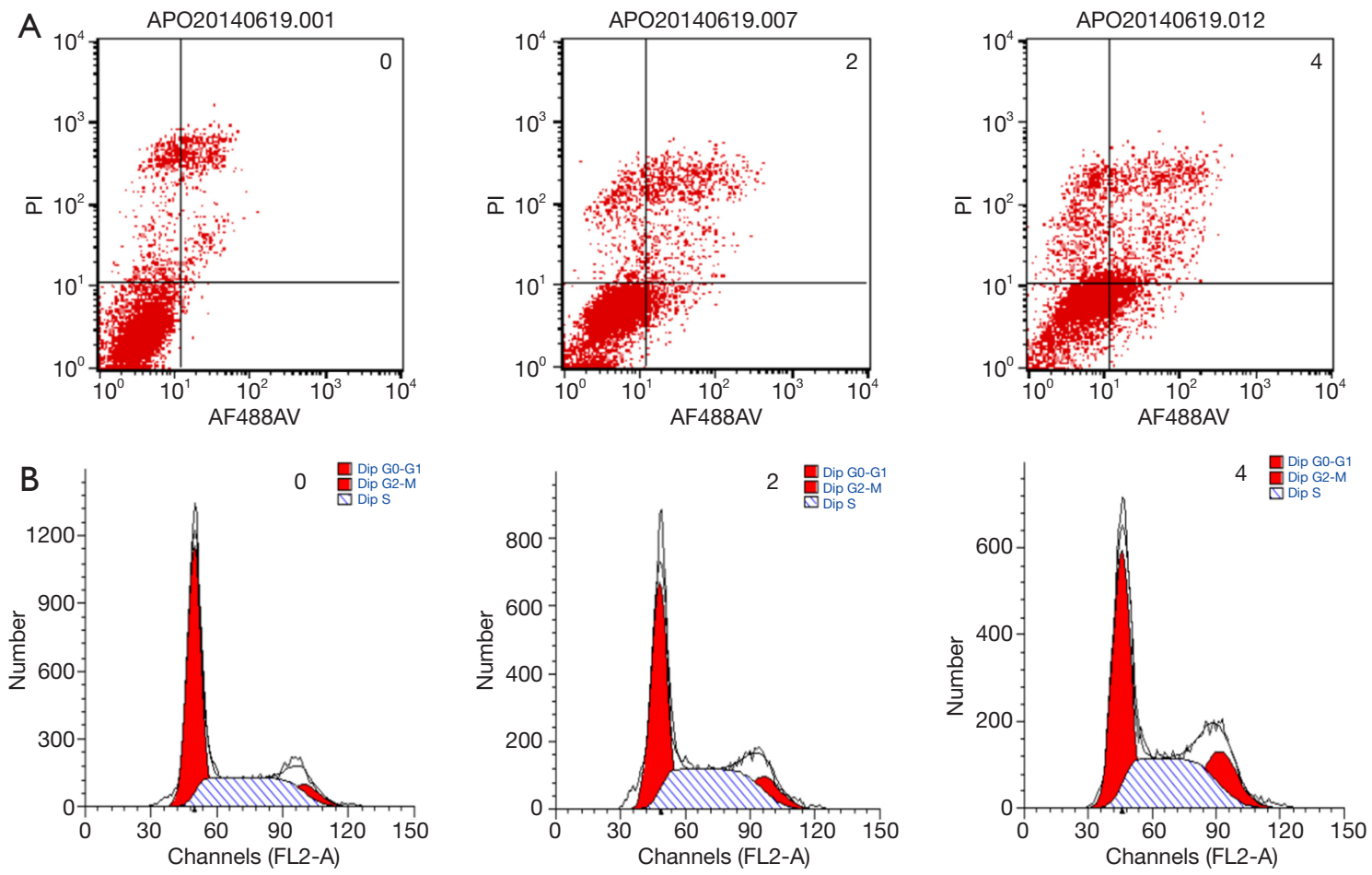

Figure 2 Effects of Crocin on the apoptosis and cell cycle of MDA-MB-231 cells. (A) The apoptosis of MDA-MB-231 increased with the increase in concentration; (B) at the same time, more and more cells were arrested at G2/M.

Table 3 Effect of crocin on the apoptosis and cell cycle of MDA-MB-231 cells (48 h)

\begin{tabular}{lcccc}
\hline \multirow{2}{*}{ Groups $(\mathrm{mg} / \mathrm{mL})$} & & Cell cycle $(\%)$ & $\mathrm{S}$ & Apoptosis rate (\%) \\
\cline { 2 - 4 } & $\mathrm{G}_{0} / \mathrm{G}_{1}$ & $\mathrm{G}_{2} / \mathrm{M}$ & $38.25 \pm 2.4$ & $7.7 \pm 2.3$ \\
2 & $50.96 \pm 6.01$ & $10.79 \pm 3.7$ & $36.98 \pm 4.26$ & $16.63 \pm 6.58^{\star *}$ \\
4 & $48.54 \pm 2.25$ & $14.48 \pm 2.35^{\star}$ & $37.52 \pm 2.17$ & $26.95 \pm 1.37^{\star *}$ \\
\hline
\end{tabular}

Compared with the control group, ${ }^{\star} \mathrm{P}<0.05$, ${ }^{\star *} \mathrm{P}<0.01$

proliferation of MDA-MB-231 tumors, mouse breast tumor models were established, which were treated with $5 \mathrm{mg} / \mathrm{mL}$ of crocin and an equivalent volume of normal saline. At 14 days after crocin treatment, the total tumor volume in the treatment group was restrained (compared to that at day zero in control group, $\mathrm{F}=3.898, \mathrm{P}=0.011$; compared to that at day zero in the treatment group, $\mathrm{F}=0.196, \mathrm{P}=0.982$ ). The results revealed that the tumor volume increased faster in the control group than in the treatment group, suggesting that crocin can inhibit the proliferation of MDA-MB-231 tumors (Figure 4).

\section{Immunobistochemical analysis}

As indicated by the brown granular staining in Figure $5 \mathrm{~A}$, CD34 was distributed around the blood vessels, and Ki67 was distributed in tumor tissues. CD34 expression in the control group and dosing group was $26 \pm 2.646$ and $14.67 \pm 4.163(\mathrm{P}<0.05)$, respectively, while the expression of $\mathrm{Ki}-67$ in the control group and treatment group was $502.67 \pm 88.484$ and $262.67 \pm 75.082(\mathrm{P}<0.05)$, respectively (Figure 5). These results show that tumor growth was slower in the $5 \mathrm{mg} / \mathrm{mL}$ crocin group, when compared to the blank 

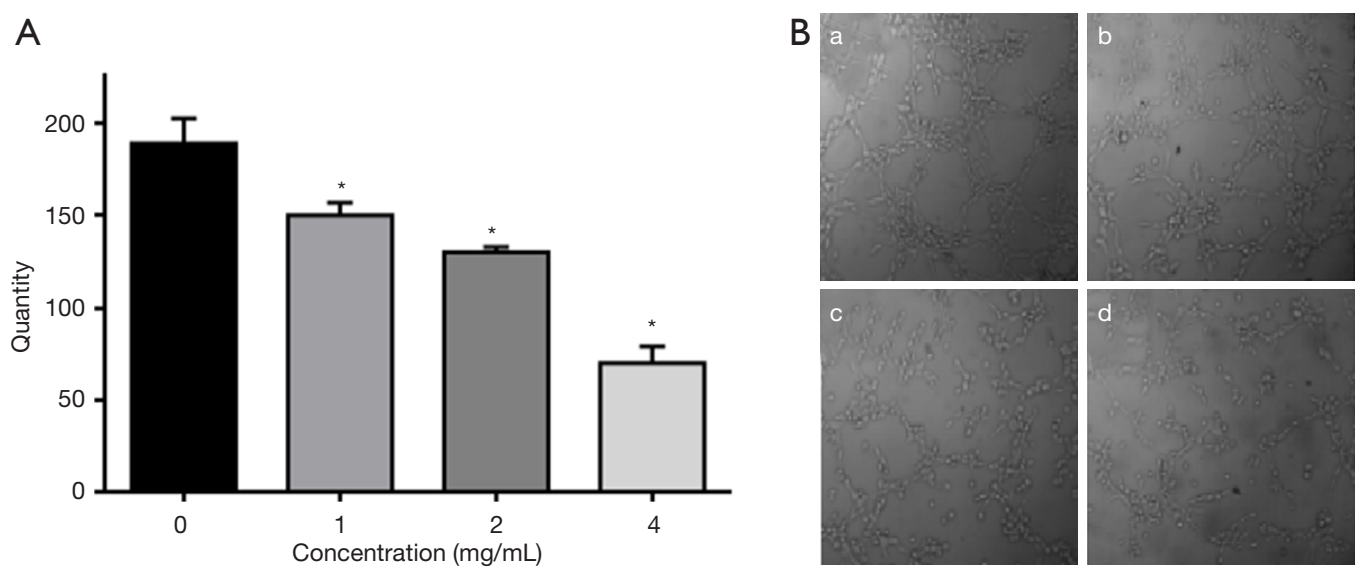

Figure 3 The way the crocin inhibits angiogenesis is as follows. (A) Effect of crocin on the migration ability of HUVECs. As shown in the figure, with the increase in drug concentration, the migration ability of umbilical vein blood cells weakened, and the number of cells was gradually reduced (note: compared with the control group, ${ }^{*} \mathrm{P}<0.05$ ). (B) Effect of crocin on the tubule formation of endothelial cells. From a to d, the drug concentration gradually increased, and the tubular cells that formed gradually decreased. HUVECs, human umbilical vein endothelial cells (bar scale: $50 \mu \mathrm{m})$.

Table 4 Crocin decreases the migration ability of human umbilical vein endothelial cells

\begin{tabular}{|c|c|c|c|c|c|c|}
\hline Group (mg/mL) & \multicolumn{6}{|c|}{ Number of cell migration } \\
\hline 0 & 170 & 238 & 199 & 165 & 172 & 189 \\
\hline 1 & 125 & 164 & 160 & 153 & 148 & $150^{*}$ \\
\hline 2 & 128 & 131 & 140 & 128 & 123 & $130^{*}$ \\
\hline
\end{tabular}

Compared with the control group, ${ }^{*} \mathrm{P}<0.05$.

Table 5 Effect of crocin on the tubule formation of endothelial cells

\begin{tabular}{lcc}
\hline Groups $(\mathrm{mg} / \mathrm{mL})$ & Number of tubes & Inhibition rate $(\%)$ \\
\hline 0 & $34 \pm 3.606$ & - \\
2.0 & $29.0 \pm 1.732^{\star}$ & 14.7 \\
4.0 & $7.67 \pm 2.887^{\star *}$ & 77.4 \\
6.0 & $4.33 \pm 1.155^{\star *}$ & 87.3 \\
\hline
\end{tabular}

Compared with the control group, ${ }^{*} \mathrm{P}<0.05$, ${ }^{\star *} \mathrm{P}<0.01$.

control group. Furthermore, the expression of CD34 and $\mathrm{Ki}-67$ in tumor tissues significantly decreased. It is possible that the anti-tumor effect of crocin was correlated with the decreasing expression of CD34 and Ki-67.

\section{Discussion}

Breast cancer is a hormone- and vascular-dependent tumor. The microvascular structure of breast cancer tissues differs from normal tissues. Due to uneven blood perfusion, increased wall permeability, and lack of lymphatic absorption exudate in breast cancer tissues, the interstitial pressure in tumor tissues is higher than that in its surrounding normal tissues. Mesenchymal infiltration contains a large number of vascular growth factors and tumor cells, resulting in tumor spreading $(15,16)$. Tumor angiogenesis not only provides nutrition and oxygen for tumor growth, but also induces tumor progression. Vascular endothelial cells are the baseline of the stroma of tumor stromal tissues that plays an important role in angiogenesis. Endothelial cell proliferation is the precondition of 

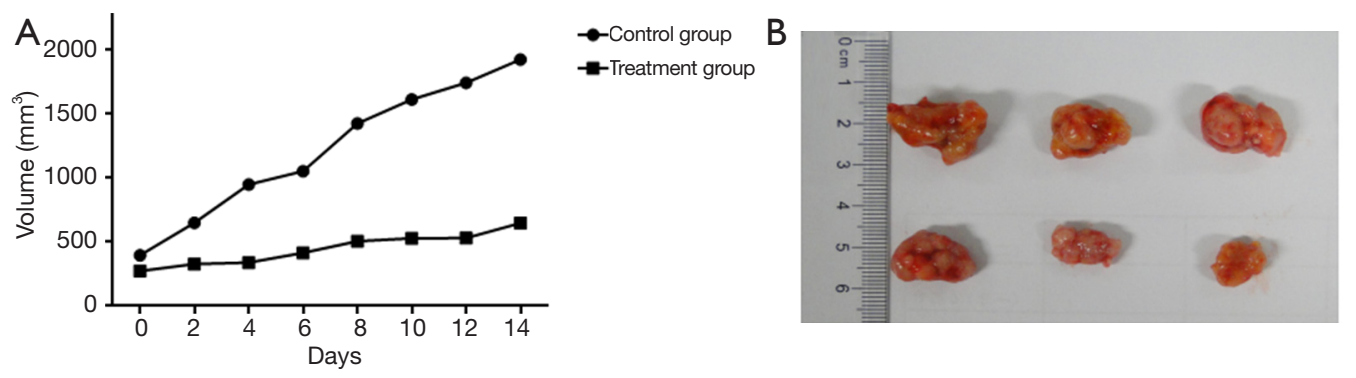

Figure 4 Inhibition curves of tumor growth and the visual map of tumor specimens after treatment. (A) After administration, the tumor volume of mice was significantly slowed down in the treatment group; (B) the tumor volume of the second row (treatment group) was significantly smaller than that of the first row (control group).
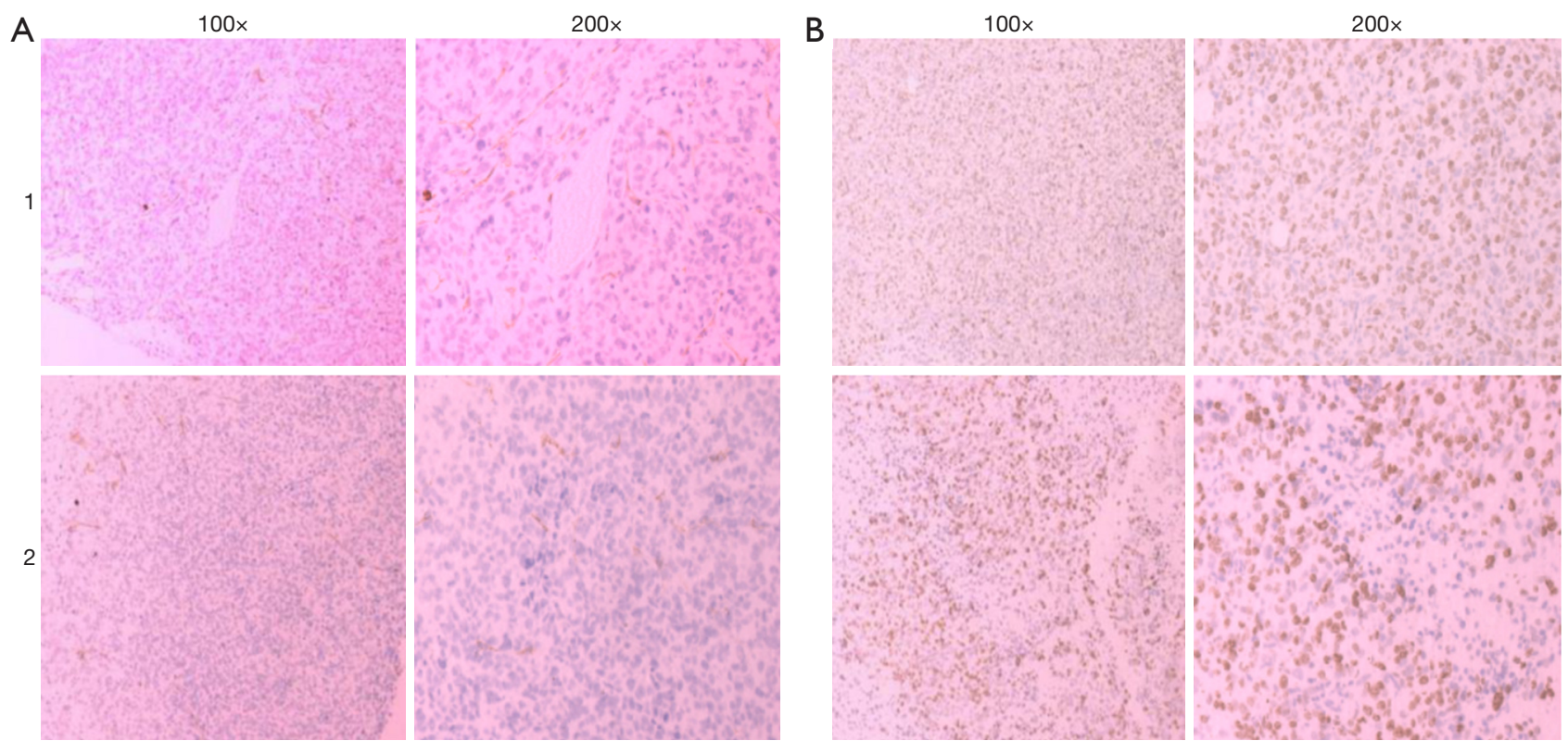

Figure 5 Immunohistochemical results (EnVision). (A) The expression of CD34; (B) the expression of Ki-67. The number one was the control group, while the number two was the treatment group. The expression of CD34 and Ki-67 were higher in the control group than in the treatment group.

angiogenesis, which makes vascular endothelial cells the main targets of anti-angiogenic therapy $(17,18)$. Vascular endothelial cells are a kind of stem cells with strong differentiation ability. These are easy to operate, and can be passaged in infinite numbers, theoretically (19). The proliferation and migration of endothelial cells in tumor interstitial tissues are enhanced due to the large number of vascular endothelial growth factors produced by tumor tissues (20). The ability of tumor angiogenesis, which promotes the recurrence and metastasis of tumors, also increases. Therefore, vascular endothelial cells are the most common cell model in the study of angiogenesis. $\mathrm{Ki}-67$ is a nuclear proliferation marker, which can positively indicate the malignancy of tumors. It is the most reliable index to evaluate the proliferation of tumor cells. CD34 widely exists in various cells that are endothelium-dependent, which are recognized on traditional vascular endothelial markers. CD34 is highly expressed in tumor angiogenesis, but is lowly expressed in normal tissues.

Crocin is a relatively rare water-soluble carotenoid extracted from the Chinese herb medicine saffron. Recently, a number of studies have shown that crocin induces an anti-tumor effect through the induction of apoptosis and cell cycle arrest, the reversal of multidrug resistance, the 
mediation of the expression of tumor regulatory factors, and so on $(12,21,22)$. However, the underlying anticancer mechanism of crocin remains incompletely understood. In the present study, it was demonstrated that crocin could inhibit tumor angiogenesis.

The present results revealed that crocin has a direct and obvious inhibitory effect on the proliferation of both MDAMB-231 breast cancer cells and subcutaneous transplanted tumors. Crocin causes cell cycle arrest at the $\mathrm{G}_{2} / \mathrm{M}$ phase in MDA-MB-231 cells in a dose-dependent manner. As for vascular endothelial cells, crocin has the following characteristics: (I) cell toxicity. The MTT assay revealed that crocin has a mild inhibitory effect on the proliferation of HUVEC cells at 24 hours, but this was not induced in a dose-dependent manner. The inhibition of its proliferation significantly increased at 48 and 72 hours, within the concentration range of $2-16 \mathrm{mg} / \mathrm{mL}$. (II) Interference in HUVEC function. The Transwell migration assay and tube formation assay revealed that crocin can significantly inhibit the migration and tubular formation ability of endothelial cells at a low dosage without cell death. Furthermore, this can also affect the function of vascular endothelial cells and prevent angiogenesis (within 24 hours of action, the concentration range was $2-6 \mathrm{mg} / \mathrm{mL}$ ). (III) Decrease in expression of CD34 in tumor tissues. The subcutaneous approach in nude mice experiments revealed that tumor growth was slower in the $5 \mathrm{mg} / \mathrm{mL}$ crocin group than in the blank control group. In addition, the expression of CD34 in the $5 \mathrm{mg} / \mathrm{mL}$ crocin group significantly decreased in tumor tissues. This suggests that crocin has an inhibitory effect on the angiogenesis of tumor tissues, and the difference was statistically significant.

Nevertheless, the underlying anti-angiogenesis mechanism of crocin remains undetermined. Tumor angiogenesis is correlated with many pathways, such as EGFR/ VEGF (23), HIF-1 $\alpha$ /VEGF (24), STAT-3/VEGF (25), and NF- $\kappa$ B/IL-6 (26). In addition, the expression of CD34 was positively correlated with VEGF. It is possible that crocin can regulate the expression of CD34 through the above pathway. From these results, it was demonstrated that crocin can inhibit tumor angiogenesis and growth through direct suppression effects on vascular endothelial cells and the reduction of pro-angiogenic factors in cancer cells. However, the molecular mechanism still requires further investigation.

\section{Conclusions}

In summary, it was discovered that crocin significantly suppressed the proliferation, migration ability and tubule formation of human UVECs, and suppressed the proliferation of breast cancer cell MDA-MB-231 and mouse breast tumor model(s). The present study confirms that crocin has an anti-angiogenesis effect. The molecular mechanism of the antiangiogenic effect of crocin may be correlated to the decreased expression of CD34. Future studies are needed to evaluate the molecular mechanisms of the antiangiogenic effect of crocin alone, or in combination with chemotherapy or molecularly targeted drugs in both in vitro and mouse breast tumor model(s).

\section{Acknowledgments}

We thank Professor Li-Ming Chen and Hong Zhao for assistance with the study.

Funding: This study was supported by Nanjing Science and Technology Project (No. 201803052) and General Hospital of Nanjing Military Region Oncology Laboratory.

\section{Footnote}

Conflicts of Interest: The authors have no conflicts of interest to declare.

Ethical Statement: The authors are accountable for all aspects of the work in ensuring that questions related to the accuracy or integrity of any part of the work are appropriately investigated and resolved.

\section{References}

1. Harbeck N, Gnant M. Breast cancer. Lancet 2017;389:1134-50.

2. Torre LA, Bray F, Siegel RL, et al. Global cancer statistics, 2012. CA Cancer J Clin 2015;65:87-108.

3. Samarghandian S, Borji A. Anticarcinogenic effect of saffron (Crocus sativus L.) and its ingredients. Pharmacognosy Res 2014;6:99-107.

4. Zhang N, Li LS. Research progress on pharmacological action of saffron (in Chinese). Drug Evaluation Research 2013;36:394-6.

5. Chen S, Zhao S, Wang X, et al. Crocin inhibits cell proliferation and enhances cisplatin and pemetrexed chemosensitivity in lung cancer cells. Transl Lung Cancer Res 2015;4:775-83.

6. Noureini SK, Wink M. Antiproliferative effects of crocin in HepG2 cells by telomerase inhibition and hTERT down- 
regulation. Asian Pac J Cancer Prev 2012;13:2305-9.

7. Hoshyar R, Bathaie SZ, Sadeghizadeh M. Crocin triggers the apoptosis through increasing the $\mathrm{Bax} / \mathrm{Bcl}-2$ ratio and caspase activation in human gastric adenocarcinoma, AGS, cells. DNA Cell Biol 2013;32:50-7.

8. Zhao P, Luo CL, Wu XH, et al. Proliferation apoptotic influence of crocin on human bladder cancer T24 cell line (in Chinese). Zhongguo Zhong Yao Za Zhi 2008;33:1869-73.

9. Sun Y, Wang Z, Wang L, et al. The Effect and Mechanisms of Proliferative Inhibition of Crocin on Human Leukaemia Jurkat Cells. West Indian Med J 2015;64:473-9.

10. Rezaee R, Mahmoudi M, Abnous K, et al. Cytotoxic effects of crocin on MOLT-4 human leukemia cells. J Complement Integr Med 2013. doi: 10.1515/jcim-2013-0011.

11. Vali F, Changizi V, Safa M. Synergistic Apoptotic Effect of Crocin and Paclitaxel or Crocin and Radiation on MCF7 Cells, a Type of Breast Cancer Cell Line. Int J Breast Cancer 2015;2015:139349.

12. Ashrafi M, Bathaie SZ, Abroun S, et al. Effect of Crocin on Cell Cycle Regulators in N-Nitroso-N-MethylureaInduced Breast Cancer in Rats. DNA Cell Biol 2015;34:684-91.

13. Weidner N, Semple JP, Welch WR, et al. Tumor angiogenesis and metastasis--correlation in invasive breast carcinoma. N Engl J Med 1991;324:1-8.

14. Hiraga T, Kizaka-Kondoh S, Hirota K, et al. Hypoxia and hypoxia-inducible factor-1 expression enhance osteolytic bone metastases of breast cancer. Cancer Res 2007;67:4157-63.

15. Jain RK, Tong RT, Munn LL. Effect of vascular normalization by antiangiogenic therapy on interstitial hypertension, peritumor edema, and lymphatic metastasis: insights from a mathematical model. Cancer Res 2007;67:2729-35.

16. Fukumura D, Jain RK. Tumor microvasculature and microenvironment: targets for anti-angiogenesis and

Cite this article as: Chen SS, Gu Y, Lu F, Qian DP, Dong TT, Ding ZH, Zhao S, Yu ZH. Antiangiogenic effect of crocin on breast cancer cell MDA-MB-231. J Thorac Dis 2019;11(11):4464-4473. doi: $10.21037 /$ jtd.2019.11.18 normalization. Microvasc Res 2007;74:72-84.

17. Hida K, Maishi N, Torii C, et al. Tumor angiogenesis-characteristics of tumor endothelial cells. Int J Clin Oncol 2016;21:206-12.

18. Yin J, Li YF, Song Y, et al. Role of miR-21 in angiogenesis of lung cancer and the effect of pemetrexed on miR-21 (in Chinese). Journal of Medical Postgraduates 2012;25:476-80.

19. Yao ZH, Yuan YD, Guo HQ, et al. Study on the anti-angiogenesis effect of oxymatrine in vivo and in vitro (in Chinese). Journal of Medical Postgraduates 2014;27:469-72.

20. Jiang L, He Y, Jiang YG. Culture of tumor-induced vascular endothelial cells and identification of cellular biological characteristics (in Chinese). Chongqing Medicine 2009;38:3102-3104, 3195.

21. Bakshi HA, Hakkim FL, Sam S. Molecular Mechanism of Crocin Induced Caspase Mediated MCF-7 Cell Death: In Vivo Toxicity Profiling and Ex Vivo Macrophage Activation. Asian Pac J Cancer Prev 2016;17:1499-506.

22. Mahdizadeh S, Karimi G, Behravan J, et al. Crocin suppresses multidrug resistance in MRP overexpressing ovarian cancer cell line. Daru 2016;24:17.

23. Yu X, Li W, Deng Q, et al. Neoalbaconol inhibits angiogenesis and tumor growth by suppressing EGFR-mediated VEGF production. Mol Carcinog 2017;56:1414-26.

24. Park JH, Yoon J, Park B. Pomolic acid suppresses HIF $1 \alpha /$ VEGF-mediated angiogenesis by targeting p38MAPK and mTOR signaling cascades. Phytomedicine 2016;23:1716-26.

25. Zhu D, Shen Z, Liu J, et al. The ROS-mediated activation of STAT-3/VEGF signaling is involved in the 27-hydroxycholesterol-induced angiogenesis in human breast cancer cells. Toxicol Lett 2016;264:79-86.

26. Liang S, Chen Z, Jiang G, et al. Activation of GPER suppresses migration and angiogenesis of triple negative breast cancer via inhibition of NF- $\mathrm{B} / \mathrm{IL}-6$ signals. Cancer Lett 2017;386:12-23. 